\title{
Tiotropium as a first maintenance drug in COPD: secondary analysis of the UPLIFT ${ }_{\circledast}$
}

trial

\author{
T. Troosters*, B. Celli ${ }^{\#}$, T. Lystig ${ }^{\star}$, S. Kesten ${ }^{\top}$, S. Mehra ${ }^{+}$, D.P. Tashkin ${ }^{\S}$ and \\ M. Decramer* on behalf of the UPLIFT ${ }_{\mathbb{B}}$ investigators $^{f}$
}

ABSTRACT: The aim of the present study was investigate the long-term effect of tiotropium as first maintenance respiratory medication in chronic obstructive pulmonary disease (COPD).

A 4-yr, randomised, multicentre, double-blind, parallel-group, placebo-controlled trial (Understanding Potential Long-term Impacts on Function with Tiotropium (UPLIFT $\mathbb{R}$ )) was conducted. Analysis focused on the effect of tiotropium versus matching placebo in the $810(13.5 \%)$ COPD patients not on other maintenance treatment (long-acting $\beta$-agonists, inhaled corticosteroids, theophyllines or anticholinergics) at randomisation. Spirometry, health-related quality of life (St George's Respiratory Questionnaire (SGRQ) score), exacerbations of COPD and mortality were also analysed.

403 patients (mean \pm SD age $63 \pm 8$ yrs, post-bronchodilator forced expiratory volume in $1 \mathrm{~s}$ (FEV 1$) 53 \pm 12 \%$ predicted) received tiotropium and 407 (64 \pm 8 yrs of age, post-bronchodilator $\mathrm{FEV}_{1} \mathbf{5 1} \pm \mathbf{1 2} \%$ pred) received placebo. Post-bronchodilator $\mathrm{FEV}_{1} \mathrm{decline}$ was $42 \pm 4 \mathrm{~mL} \cdot \mathrm{yr}^{-1}$ in the tiotropium group and $53 \pm 4 \mathrm{~mL} \cdot \mathrm{yr}^{-1}$ in the placebo group $(p=0.026)$. At 48 months, the morning pre-dose FEV1 was $134 \mathrm{~mL}$ higher in the tiotropium group compared to the placebo group $(p<0.001)$. SGRQ total score declined more slowly in the tiotropium group (difference of $1.05 \pm$ 0.34 units $\mathrm{yr}^{-1} ; \mathrm{p}=\mathbf{0 . 0 0 2}$ ). This was particularly significant for the impact (difference of $1.08 \pm 0.37$ units $\left.\cdot \mathrm{yr}^{-1} ; \mathrm{p}=0.004\right)$ and activity $\left(1.44 \pm 0.40\right.$ units $\left.\cdot \mathrm{yr}^{-1} ; \mathrm{p}<0.001\right)$ domains, but not for symptoms $\left(0.26 \pm 0.50\right.$ units $\left.\mathrm{yr}^{-1} ; \mathrm{p}=0.6\right)$. At 48 months, the difference in total score was 4.6 units $(p<0.001)$ with tiotropium compared to placebo.

In patients with COPD who are not on maintenance therapy, tiotropium is associated with significant benefits in disease progression.

KEYWORDS: Anticholinergic agent, chronic obstructive pulmonary disease, disease progression, exacerbation, lung function, quality of life

hronic obstructive pulmonary disease (COPD) is an increasingly important health problem. In Sweden, the 30-yr incidence of COPD has been reported to be $32 \%$ in smokers [1]. More recently, data from the Netherlands have determined that the risk of developing COPD in 40 yrs of follow-up for a 55 yr old without COPD was $24 \%$ for males and $16 \%$ for females [2]. Together, the data indicate that clinicians will continue to be confronted by newly detected patients with COPD.

The main focus of therapy is to relieve symptoms, prevent disease progression, improve exercise tolerance and health status, prevent exacerbations and improve survival, preferably by using interventions with a favourable safety profile [3]. Initial therapy involves preventive measures and often, use of a short-acting bronchodilator as needed. However, given the known progression of COPD, patients who become symptomatic will eventually require maintenance medications. Present guidelines provide several options for first-line maintenance pharmacotherapy, yet sparse data exist regarding the outcome that can be expected upon first prescription of initial medication [3]. In particular, knowledge of the long-term effect of pharmacotherapy on lung function, health-related quality of life (HRQoL) and exacerbations is important to guide the management of these patients and set-up disease management plans for years rather than months.

For editorial comments see page 10.

This article has supplementary material accessible from www.erj.ersjournals.com

AFFILIATIONS

* Respiratory Division and Dept of Rehabilitation Sciences, Katholieke Universiteit Leuven, Leuven, Belgium. "Brigham and Women's Hospital, Harvard Medical School, Boston, MA 'Boehringer Ingelheim Pharmaceuticals, Ridgefield, CT, +Pfizer, New York, NY, ${ }^{\S}$ David Geffen School of Medicine at UCLA, Los Angeles, CA, USA. ${ }^{f} A$ full list of the UPLIFT ${ }_{\mathbb{B}}$ investigators is provided in the Acknowledgements.

CORRESPONDENCE T. Troosters

Respiratory Division and Pulmonary Rehabilitation

UZ Gasthuisberg

Herestraat 49 B3000 Leuven Belgium

E-mail: thierry.troosters@ med.kuleuven.be

Received: Aug 112009 Accepted after revision: Feb 092010 First published online: Feb 252010 
Studies in patients who are not yet on maintenance respiratory therapy are needed to assist healthcare professionals in decision-making regarding their choice of initial treatment. The Understanding Potential Long-term Impacts on Function with Tiotropium (UPLIFT ${ }_{\circledR}$ ) trial [4-6] offers a unique opportunity to gain insight into using tiotropium as a first maintenance drug in COPD. In the 4-yr UPLIFT ${ }_{\circledast}$ trial, patients were randomised into a group receiving tiotropium $18 \mu \mathrm{g}$ once daily or matching placebo. All patients who were permitted use of all maintenance therapies, other than inhaled anticholinergics, as prescribed by their physicians throughout the trial.

The main results of the effect of tiotropium on lung function, health-related quality of life, exacerbation rate and mortality are presented elsewhere $[4,5]$.

The aim of the present study was to investigate the clinical outcomes, including disease progression, in patients who were naïve to maintenance therapy prior to randomisation. Disease progression was evaluated in terms of lung function decline, evolution of HRQoL, exacerbation rate, survival, and the initiation of other concomitant medication during the trial.

\section{METHODS}

Details of the study design were previously reported by DECRAMER et al. [6] and are summarised below. The primary analysis is reported elsewhere [4].

\section{Study design}

The study was a 4-yr, randomised, double-blind, placebocontrolled, parallel-group trial performed in patients with moderate to very severe COPD. The two co-primary endpoints were yearly rate of decline in pre-bronchodilator (morning pre-study drug) forced expiratory volume in $1 \mathrm{~s}$ (FEV1) and post-bronchodilator FEV1 from day 30 (steady state) until completion of double-blind treatment. Secondary outcome measures included the rate of decline in forced vital capacity (FVC) and slow vital capacity, spirometry at each clinic visit, HRQoL as measured by the St George's Respiratory Questionnaire (SGRQ) total score [7], exacerbations (as defined below) and related hospitalisations, and mortality (all-cause and lower respiratory).

The treatment arms were tiotropium $18 \mu \mathrm{g}$ once daily or matching placebo delivered via the HandiHaler ${ }_{\circledast}$ inhalation device (Boehringer Ingelheim $\mathrm{GmbH} \& \mathrm{Co}$. KG, Ingelheim, Germany). In the UPLIFT ${ }_{\circledast}$ trial, all patients were permitted to continue or modify respiratory medications, other than inhaled anticholinergics, as prescribed by their physicians throughout the trial. The present analysis investigated the subgroup of patients who were not receiving any maintenance respiratory medications at screening. This cohort represented 810 subjects of the original 5,993 patients included in the UPLIFT ${ }$ tiral $(13.5 \%$ of the total UPLIFT ${ }^{\circledR}$ cohort). The time of initiation of other respiratory drugs was recorded in the case report forms. Smoking cessation was offered to all patients prior to randomisation, and self-reported smoking behaviour was recorded at each visit. Salbutamol could be used as-needed for relief of symptoms.

\section{Participants}

Patients were recruited between January 2003 and March 2004 from 490 investigational centres in 37 countries in Asia, South
America, North America, Europe, South Africa, Australia and New Zealand. Patients were recruited from academic and nonacademic medical practices. Criteria for participation included diagnosis of COPD, $\geqslant 40 \mathrm{yrs}$ of age, smoking history of $\geqslant 10$ pack-yrs, and post-bronchodilator $\mathrm{FEV} 1 \leqslant 70 \%$ of the predicted normal [8] and FEV1 $\leqslant 70 \%$ of FVC. Key exclusion criteria were a history of asthma, a COPD exacerbation or respiratory infection within 4 weeks of screening, a history of pulmonary resection, use of supplemental oxygen $>12 \mathrm{~h} \cdot$ day $^{-1}$, or a significant disease other than COPD that could preclude participation in the study or interfere with the study results. Patients on maintenance respiratory medications (inhaled long-acting $\beta$-agonists (LABA), inhaled corticosteroids (ICS), theophyllines or anticholinergics) were excluded for the purposes of the current analysis. The protocol was approved by the ethics committee of each centre and all patients provided written informed consent.

\section{Procedures}

After a screening period, eligible patients were randomised using a centralised pseudo random-number generator, accessed through an interactive voice response system, 1:1 to tiotropium or placebo in blocks of four stratified by site. Post-randomisation clinic visits occurred at 1 and 3 months, and then every 3 months throughout the 4-yr treatment period.

Spirometry was performed according to American Thoracic Society (ATS) guidelines [9]: at randomisation; at 30 days and every 6 months throughout the treatment period; and at a follow-up visit $\sim 30$ days after the end of study treatment. Prior to spirometry testing, respiratory medications were withheld as follows: study drug $24 \mathrm{~h}$; inhaled steroid morning dose $12 \mathrm{~h}$; short-acting $\beta$-agonist $8 \mathrm{~h}$; short-acting theophyllines (b.i.d. or q.i.d.) and LABA (including fixed combination with inhaled steroids) $24 \mathrm{~h}$; and once-daily theophyllines $48 \mathrm{~h}$. Spirometry was performed prior to bronchodilator administration (prebronchodilator) and 90 min post-bronchodilator (i.e. following bronchodilator administration using four actuations of ipratropium (total $80 \mu \mathrm{g}$ ), followed by four actuations of albuterol (total $400 \mu \mathrm{g}$ ) $60 \mathrm{~min}$ later). Study drug was administered immediately after pre-bronchodilator spirometry and just prior to short-acting bronchodilator administration. Sites were provided with identical spirometry equipment and studyspecific software.

HRQoL was measured using the SGRQ [7] prior to prebronchodilator spirometry testing at baseline and every 6 months. Adverse events were collected at each visit.

Exacerbations were defined as an increase in or new onset of more than one respiratory symptom (cough, sputum, sputum purulence, wheezing, dyspnoea) with a duration of $\geqslant 3$ days, requiring treatment with an antibiotic and/or systemic steroid. Data from exacerbations and related hospitalisations were collected on study-specific case report forms at every visit.

Information concerning concomitant respiratory maintenance medications and the date at which they were commenced were retrieved from the case report forms as reported by the treating physician. Classes of respiratory maintenance medication were ICS, inhaled LABA, combinations of ICS and LABA (LABA/ ICS), either fixed or using the two products separately, and theophyllines. 


\section{Statistical methods}

The statistical methods used to analyse the end-points have been described previously [4]. The present study used the same approach for all its statistical analyses, with the exception that the analyses were restricted to the specified subset of patients. Briefly, FEV1 and FVC decline were analysed using a normal random-effects model in which the measurement changed linearly after day 30 for each subject, where the intercepts and slopes among subjects were assumed to be random with an arbitrary covariance matrix, and with a fixed treatment effect [10]. All randomised and treated patients who were maintenance-naïve at baseline were included in these analyses if they had at least three lung function assessments from day 30 onwards. HRQoL (SGRQ total score and its subdomains) were analysed using the same technique (from 6 months until completion of treatment). At least two SGRQ assessments were needed from month 6 onwards in order to be included in these analyses. As likelihood-based methods were employed to handle missing data for the random coefficient regression analysis, no imputation was necessary. Analyses of heterogeneity of subgroups were assessed by testing for interaction between treatment group slope and each baseline factor. The mean effects at various visits were compared across treatment groups using repeated measures ANCOVA without imputation of missing values. SGRQ data from Turkey were excluded due to incorrect validation of the questionnaire.

The time to first exacerbation and associated hospitalisations were compared between treatment groups using log-rank tests, and were pre-specified as the key secondary analyses. Cox regression was used to derive hazard ratios (HR). The number of events and event days were compared between treatment groups using Poisson regression with correction for treatment exposure and over-dispersion [11].
Incidence rates were computed as number of patients with events divided by time at risk. For survival, both on-treatment and intent-to-treat analyses were carried out.

Possible differences in baseline variables between treatment groups were evaluated using unpaired t-tests for continuous variables, normal approximation to binominal tests for binary data, and Pearson Chi-squared tests for other categorical data. These tests were also used to evaluate possible differences in baseline variables between patients on maintenance therapy and those naïve to maintenance therapy.

All reported p-values are two-sided and not adjusted for multiple testing; the nominal alpha was set a priori at 0.05 .

\section{RESULTS}

A total of 810 patients not receiving maintenance respiratory medications at baseline were identified (403 tiotropium, 407 placebo) (fig. 1). Compared to those who were treated with maintenance therapies at baseline, the maintenance-naïve group was younger, included more smokers, had a shorter history of COPD, and had better lung function (table 1). The geographic distribution of patients differed between the maintenance-naïve group and those treated with maintenance therapies. There were proportionally more Europeans but proportionally fewer subjects from the USA and Latin America (the percentages from Asia were similar). All of the differences described were highly statistically significant $(p<0.0001)$.

While the maintenance-naïve group as a whole differed markedly from those who were not maintenance-naïve, the tiotropium and placebo groups were well balanced within each of the two maintenance therapy categories. When considering region as a whole among those who were maintenance-naïve, the Pearson Chi-squared test for association between region and treatment group was nonsignificant (Chi-squared 7.94, $\mathrm{p}=0.09$ ).

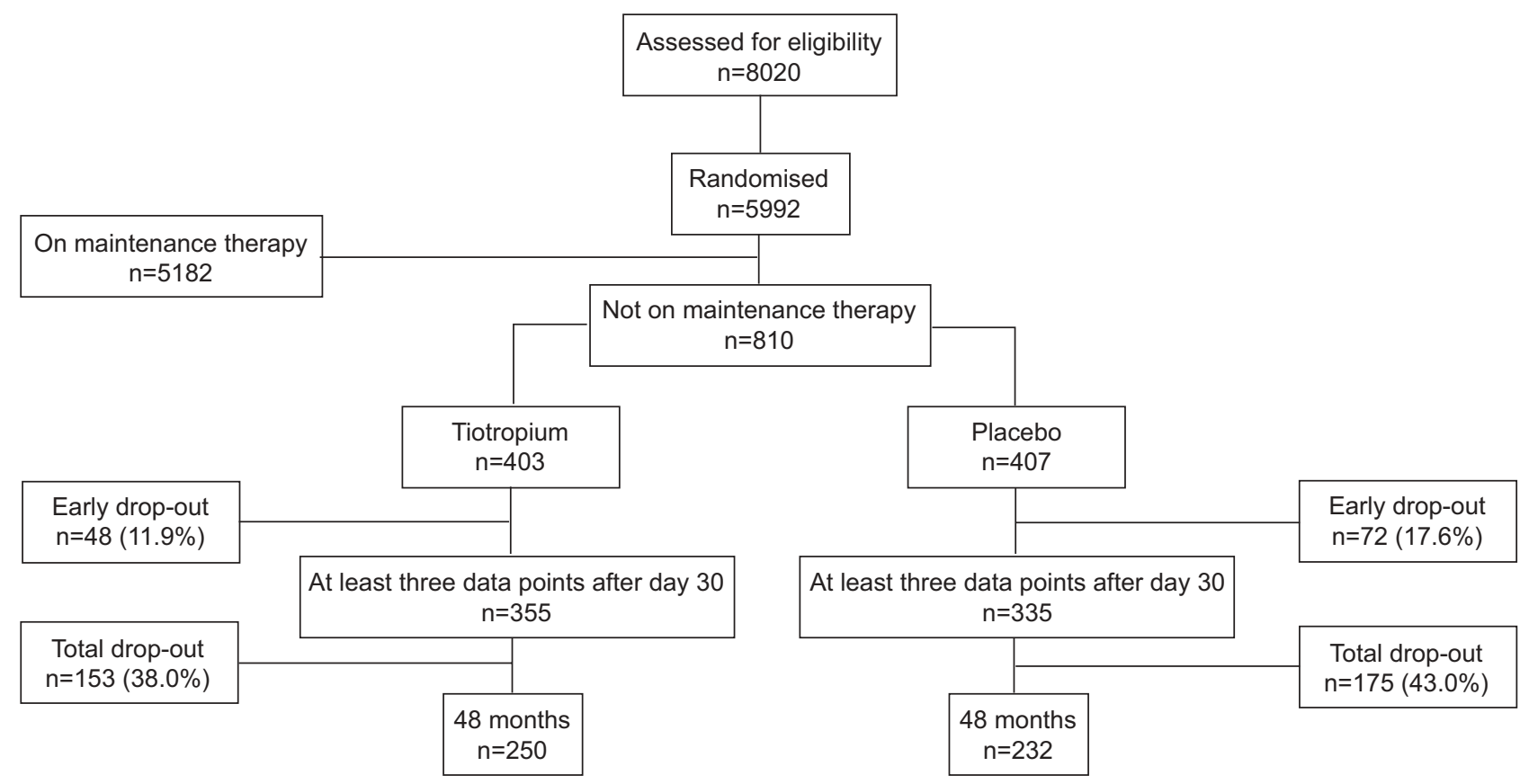

FIGURE 1. Disposition of maintenance-naive patients. The sub-analysis of the present study focuses on a subgroup of the original Understanding Potential Long-term Impacts on Function with Tiotropium (UPLIFT $\mathbb{R}_{\mathbb{E}}$ ) trial. 


\begin{tabular}{|c|c|c|c|c|c|c|}
\hline & \multicolumn{4}{|c|}{ MN-naïve population } & \multicolumn{2}{|c|}{ UPLIFT $\circledast_{\circledast}$ population } \\
\hline Subjects $n$ & 403 & 407 & & 810 & 5182 & \\
\hline Age yrs & $63 \pm 8$ & $64 \pm 8$ & 0.20 & $63 \pm 8$ & $65 \pm 8$ & $<0.001$ \\
\hline BMI $\mathrm{kg} \cdot \mathrm{m}^{-2}$ & $26 \pm 6$ & $26 \pm 5$ & 0.36 & $26 \pm 6$ & $26 \pm 5$ & 0.45 \\
\hline COPD history yrs & $9 \pm 8$ & $9 \pm 7$ & 0.86 & $9 \pm 7$ & $10 \pm 7$ & $<0.001$ \\
\hline Pre FEV $1 \%$ pred & $44 \pm 11$ & $43 \pm 12$ & 0.21 & $44 \pm 12$ & $39 \pm 12$ & $<0.001$ \\
\hline Post FEV $1 \%$ pred & $53 \pm 12$ & $51 \pm 12$ & 0.08 & $52 \pm 12$ & $47 \pm 13$ & $<0.001$ \\
\hline Pre FVC \% pred & $77 \pm 16$ & $77 \pm 17$ & 1.00 & $77 \pm 17$ & $75 \pm 18$ & $<0.001$ \\
\hline IV & 4 & 6 & & 5 & 9 & \\
\hline \multicolumn{7}{|l|}{ Region } \\
\hline Asia & 8.2 & 4.7 & 0.09 & 6.4 & 6.0 & $<0.001$ \\
\hline Eastern Europe & 9.2 & 7.9 & & 8.5 & 21.6 & \\
\hline Latin America & 16.6 & 16.1 & & 16.3 & 5.3 & \\
\hline USA & 39.7 & 38.1 & & 38.9 & 23.5 & \\
\hline Western Europe & 26.3 & 33.4 & & 29.9 & 43.7 & \\
\hline
\end{tabular}

Data are presented as mean \pm SD or \%, unless otherwise stated. For reference purposes, the characteristics of the remaining Understanding Potential Long-term Impacts on Function with Tiotropium (UPLIFT $\mathbb{\varepsilon}$ ) patients are given [4]. MN: maintenance; M: male; F: female; BMI: body mass index; COPD: chronic obstructive pulmonary disease; Pre: pre-bronchodilator; Post: post-bronchodilator; FEV1: forced expiratory volume in 1 s; \% pred: \% predicted; FVC: forced vital capacity; GOLD: Global Initiative for Chronic Obstructive Lung Disease. No statistically significant differences were observed between tiotropium-treated and placebo-treated patients at baseline. The p-values refer to the comparison of tiotropium versus placebo or the MN-naive patients compared to the remaining patients included in UPLIFT

In the maintenance-naïve study population, there were slightly more Asian $(\mathrm{p}=0.04)$ and slightly less Western European $(\mathrm{p}=0.03)$ subjects in the tiotropium group compared to the placebo group.

A slightly lower proportion of patients prematurely discontinued the trial in the tiotropium group (38.0 versus $43.0 \%$; $\mathrm{p}=0.14$ ).

\section{Baseline characteristics of the maintenance-naïve patients}

Baseline characteristics were balanced between treatment groups (table 1). Approximately $73 \%$ of patients were males and mean age was $63 \pm 8$ years and $43.1 \%$ were active smokers. Patients, on average, had moderate airflow obstruction (postbronchodilator FEV1 $52 \pm 12 \%$ predicted) with significant bronchodilator response. FEV1 increased by $21 \pm 17 \%$ of the pre-bronchodilator value after the inhalation of ipratropium and salbutamol. The majority of patients were in GOLD II and III with only $5 \%$ having GOLD stage IV. Their baseline SGRQ total score was $41 \pm 18$ units.

\section{Lung function}

Table 2 presents the lung function variables observed throughout the trial. After 30 days of treatment, pre-bronchodilator (trough) FEV1 was $99 \pm 15 \mathrm{~mL}(\mathrm{p}<0.0001)$ larger in tiotropium compared to placebo. Trough FEV1 remained significantly larger in tiotropium compared to control throughout the trial $(\mathrm{p}<0.05$ at all time points), with a benefit ranging $99-160 \mathrm{~mL}$ (fig. 2).
Annual decline in lung function after the first month of treatment was slower in tiotropium compared to placebo.

\section{HRQOL}

HRQoL improved in the tiotropium group compared to the placebo group. SGRQ total score improved in the first 6 months in both groups, but the improvement was -2.29 (95\% CI -3.94- -0.65; $\mathrm{p}=0.0065)$ units larger in the tiotropium group (fig. 3a). The difference between both groups was also significant for all domains of the SGRQ (fig. 3b-d). The annual decline in HRQoL after month 6 was faster in the placebo group compared to the tiotropium group. The total score of the SGRQ worsened by $1.71 \pm 0.24$ units $\cdot \mathrm{yr}^{-1}$ in the placebo group and $0.66 \pm 0.23$ units $\cdot \mathrm{yr}^{-1}$ in the tiotropium group $(\mathrm{p}=0.0019$ between groups). As a consequence, the difference between groups increased over time and reached -4.57 units $\cdot \mathrm{yr}^{-1}(95 \%$ CI -7.06- -2.09) after 4 yrs of treatment (fig. 3). Decline in symptom score was not different between groups, whereas the differential decline in the impact $\left(-1.08 \pm 0.37\right.$ units $\cdot \mathrm{yr}^{-1}$; $\mathrm{p}=0.004)$ and the activity $\left(-1.44 \pm 0.40\right.$ units $\left.\cdot \mathrm{yr}^{-1} ; \mathrm{p}=0.0004\right)$ domains significantly favoured the tiotropium group.

\section{Exacerbations}

In the placebo and tiotropium groups, 56.5 and $55.6 \%$ of the participants, respectively, experienced at least one exacerbation. The exacerbation rate with tiotropium was $16 \%$ lower than with placebo but this did not reach statistical significance $(0.49$ and 


\begin{tabular}{|c|c|c|c|c|c|}
\hline \multirow[t]{2}{*}{ TABLE 2} & \multicolumn{5}{|c|}{$\begin{array}{l}\text { Lung function at baseline (day 1), } 1 \text { month after randomisation and at the end of the study ( } 4 \text { yrs) in the placebo and } \\
\text { tiotropium group, pre- and post-bronchodilator }\end{array}$} \\
\hline & 1 day $L$ & 1 month L & 4 yrs L & Decline $^{\#} \mathrm{~mL} \cdot \mathrm{yr} \mathrm{r}^{-1}$ & p-value $e^{\circ}$ \\
\hline Pre FEV 1 & & & & & 0.049 \\
\hline Placebo & $1.21 \pm 0.02$ & $1.25 \pm 0.01$ & $1.09 \pm 0.01$ & $45 \pm 4$ & \\
\hline Tiotropium & $1.25 \pm 0.02$ & $1.35 \pm 0.01^{\star \star *}$ & $1.22 \pm 0.01^{\star * *}$ & $35 \pm 3$ & \\
\hline Tiotropium & $1.50 \pm 0.02$ & $1.56 \pm 0.01^{* \star \star}$ & $1.40 \pm 0.01^{\star \star \star}$ & $42 \pm 4$ & \\
\hline Pre FVc & & & & & 0.084 \\
\hline Placebo & $2.73 \pm 0.05$ & $2.76 \pm 0.02$ & $2.57 \pm 0.03$ & $56 \pm 7$ & \\
\hline Tiotropium & $2.73 \pm 0.04$ & $2.95 \pm 0.02^{\star \star \star}$ & $2.81 \pm 0.03^{\star \star \star}$ & $38 \pm 7$ & \\
\hline Post FVC & & & & & 0.081 \\
\hline Tiotropium & $2.87 \pm 0.04$ & $3.08 \pm 0.02^{\star \star \star}$ & $2.94 \pm 0.03^{\star * \star}$ & $35 \pm 7$ & \\
\hline Post SvC & & & & & 0.006 \\
\hline Placebo & $3.23 \pm 0.05$ & $3.31 \pm 0.05$ & $3.06 \pm 0.03$ & $67 \pm 7$ & \\
\hline Tiotropium & $3.24 \pm 0.05$ & $3.31 \pm 0.02$ & $3.14 \pm 0.03^{+}$ & $39 \pm 7$ & \\
\hline
\end{tabular}

Data are presented as mean \pm SEM, unless otherwise stated. Pre: pre-bronchodilator; Post: post-bronchodilator; FEV1: forced expiratory volume in 1 s; FVC: forced vital capacity; SVC: slow vital capacity. *: annual decline in the lung function parameter (refer to the Statistical methods section for the calculation); ": comparison between groups. ${ }^{* *}: p<0.001 ;{ }^{+}: p=0.06$.

0.58 exacerbations $\cdot \mathrm{yr}^{-1}$ with tiotropium and placebo, respectively; $\mathrm{p}=0.08$; figure 1 of the online supplementary material). The time to the first exacerbation did not differ significantly between groups: 26.9 months (95\% CI 20.2-33.0) months in tiotropium versus 20.6 months (95\% CI 17.5-25.2) months in placebo $(\mathrm{p}=0.24)$. Only $17 \%$ of patients experienced an exacerbation leading to a hospital admission. No significant differences were observed between groups.

\section{Mortality}

In the placebo group, $56(13.8 \%)$ patients died during the study while on treatment. In the tiotropium group, $44(10.9 \%)$ patients died (HR 0.74 (95\% CI 0.50-1.10); $\mathrm{p}=0.14$; Figure 2 of the online supplementary material). Using an intent-to-treat analysis, including patients who dropped out of the study, these percentages were 15.7 for the placebo group and 12.2 for the tiotropium group (HR 0.76 (95\% CI 0.53-1.11); p=0.16). Ontreatment mortality due to lower respiratory tract disorders was $5.2 \%$ in the placebo group and $3.2 \%$ in the tiotropium group (HR 0.59 (95\% CI 0.29-1.17); $\mathrm{p}=0.13$ ).

\section{Initiation of other respiratory maintenance therapy}

In the tiotropium group, $37 \%$ of the patients completed the study without taking concomitant LABA and/or ICS during the study. In the placebo group, this was $28 \%$ of the initially enrolled patients. The remainder of the patients prematurely discontinued participation in the trial or started using at least one of these maintenance therapies before the end of the trial. Tiotropium was associated with a lower risk for commencement of ICS: HR 0.76 (95\% CI 0.61-0.94; p=0.01); for commencement of LABA: HR 0.72 (95\% CI 0.57-0.91; $\mathrm{p}=0.006)$; and for ICS/ LABA: HR 0.77 (95\% CI $0.60-0.99 ; \mathrm{p}=0.04)(\mathrm{p}<0.05$ overall).
The subsequent on-trial use of both LABA and ICS was 31.9\% in the placebo group and $25.8 \%$ in the tiotropium group.

\section{DISCUSSION}

The present report, a secondary analysis of a specific subgroup of patients from the UPLIFT ${ }_{\circledast}$ study, shows evidence of slowing COPD progression in patients in whom tiotropium is commenced as the first maintenance respiratory drug. This is supported by a better preserved and slower declining lung function and HRQoL. As expected, the present study demonstrates an initial treatment effect but the effect becomes larger over time. After 4 yrs of treatment, patients in the tiotropium group showed a clinically important difference in HRQoL. In addition, trough FEV1 was $134 \mathrm{~mL}$ better in patients treated with tiotropium compared to control subjects and postbronchodilator FEV1 (i.e. following inhalation of study drug and four actuations of both ipratropium and salbutamol) was $96 \mathrm{~mL}$ larger in those patients treated with tiotropium.

The present study investigates a relatively small (13.5\%) but particularly interesting sample of patients randomised in the $\mathrm{UPLIFT}_{\circledR}$ trial. Due to the large sample size of the UPLIFT ${ }_{\mathbb{R}}$ study, the relatively small proportion of patients still yields an appreciable sample size $(n=810)$ of a clinically interesting subgroup of patients with COPD recruited into clinical trials: patients naïve to maintenance respiratory therapy at inclusion. This group of patients is particularly interesting for clinicians faced with the choice of prescribing a first maintenance treatment to patients with COPD.

In the UPLIFT ${ }_{\circledR}$ study, patients were allowed to take all concomitant maintenance respiratory therapy as prescribed, with the exception of inhaled anticholinergic agents. Permitted 


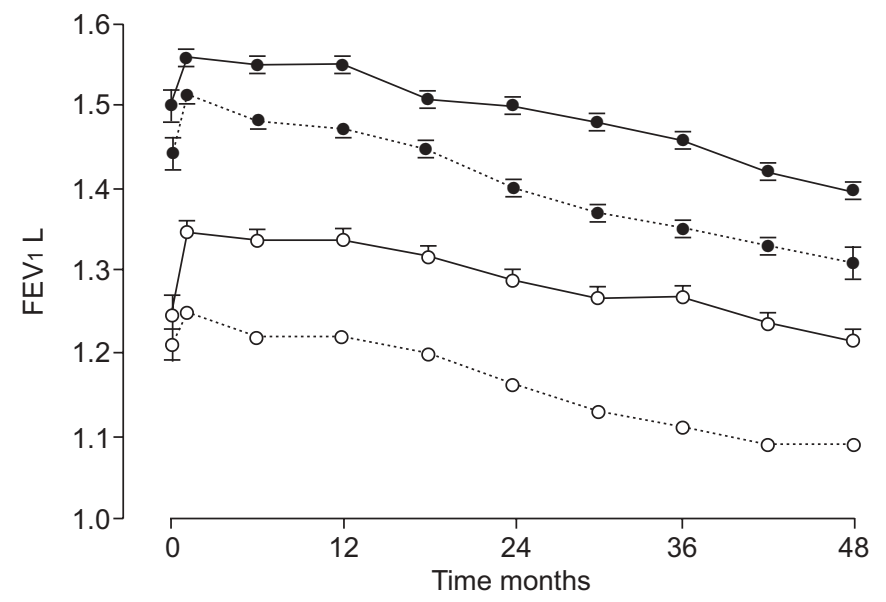

FIGURE 2. Mean forced expiratory volume in $1 \mathrm{~s}\left(\mathrm{FEV}_{1}\right)$ at each clinic visit in the tiotropium (-) and placebo (---) groups. ○: pre-bronchodilator; $\bullet$ : postbronchodilator.

medications included ICS, LABA, theophyllines and combinations of the aforementioned. Hence, UPLIFT $T_{\circledast}$ investigated the effect of prescribing tiotropium in a broad cohort of COPD patients in ways similar to community practice in order to achieve trial results relevant to healthcare prescribers. In the entire cohort of patients, there was a clear benefit of tiotropium in the setting of usual care (with the exception of the use of inhaled anticholinergics) on lung function and HRQoL, but the rate of decline of these variables was not affected (i.e. tiotropium and placebo patients subsequently declined at a similar rate). While speculative due to the liberal concomitant medication scheme, the use of other respiratory maintenance drugs [12] may have resulted in a ceiling effect, thereby diminishing the magnitude of the potential benefit of tiotropium.

In the patients who were naïve to maintenance treatment, FEV1 decline was faster than that observed in patients on maintenance therapy. In the placebo group, the annual pre-bronchodilator FEV1 decline was $45 \mathrm{~mL} \cdot \mathrm{yr}^{-1}$, whereas it was only $30 \mathrm{~mL} \cdot \mathrm{yr}^{-1}$ in the patients in the placebo group of the whole UPLIFT ${ }_{\circledast}$ cohort. It is acknowledged that there may be confounders such as the rate of smoking cessation, as well as other therapies that could potentially influence the magnitude of the results. Several possible explanations can be sought to explain our findings.

First, it is tempting to speculate that appropriate drug therapy in COPD may counterbalance decline in lung function over time, resulting in a ceiling effect for FEV1 decline in patients who are treated with maintenance respiratory therapy. The present cohort were not receiving maintenance therapy at the beginning of the study, and tiotropium or matching placebo was initiated as the initial maintenance therapy. Furthermore, $36 \%$ of patients in the placebo group and $47 \%$ of patients in the tiotropium group remained maintenance-naive in the data included in the analysis of decline in lung function, HRQoL and exacerbations, which is a larger proportion than in the complete UPLIFT ${ }_{B}$ cohort.

Secondly, there is a difference in the geographical origin of patients in the present subanalysis compared to the complete cohort. To our knowledge, however, none of the data suggest a different decline in lung function based on geography, and there is no evidence of differing responsiveness to tiotropium.
Thirdly, the number of current smokers in the present cohort of patients was larger than in the formerly reported full UPLIFT ${ }^{\circledR}$ cohort (43.1 versus $29.6 \%$ ). A secondary analysis of the UPLIFT ${ }_{\circledast}$ cohort showed a steeper decline in lung function in smokers. However, it is noteworthy that there was no difference in the rate of decline in lung function with tiotropium when smokers where compared to ex-smokers [13].

A fourth explanation may be that the lung function of this cohort of patients was still better preserved ( 52 versus $47 \%$ pred in the group on maintenance therapy). Consequently, the likelihood of reaching a floor effect in lung function decline would be smaller in the maintenance-naive patients [14]. This explanation can only partially explain the difference because in another pre-planned secondary analysis of the UPLIFT ${ }_{B}$ data [15], Global Initiative for Chronic Obstructive Lung Disease (GOLD) Stage II patients (mean post-bronchodilator FEV1 59\% predicted) showed a lung function decline of $35 \mathrm{~mL} \cdot \mathrm{yr}^{-1}$, which is less than in the current subanalysis. Similarly, the fact that the present patients were slightly younger may have biased the results [16], but the difference between the age of the present patients and those on maintenance therapy was very small (1.36 yrs). Most of the patients in previous study [16], however, had concomitant medication, rendering the absence of maintenance medication, the first proposed mechanism, the most plausible explanation.

Regardless of the explanation, it is clear that patients who received tiotropium had an initial improvement in lung function, as expected; importantly, though, the subsequent decline in lung function was also improved. The difference between both randomisation groups was $10 \mathrm{~mL} \cdot \mathrm{yr}^{-1}$ before and $11 \mathrm{~mL} \cdot \mathrm{yr}^{-1}$ after administering full bronchodilation. Although these may seem small values at first sight, they are comparable to those observed in the post hoc analysis of salmeterol and fluticasone, as reported in the Toward a Revolution in COPD Health (TORCH) study [12]. In that study, the decline in FEV1 with combination salmeterol and fluticasone was $16 \mathrm{~mL} \cdot \mathrm{yr}^{-1}$ slower than in the placebo group. In the groups treated with LABA and ICS, it was $13 \mathrm{~mL} \cdot \mathrm{yr}^{-1}$ slower. Together with the acute treatment effect of tiotropium $(99 \mathrm{~mL}$, which seems to be maintained throughout the study), the total difference between patients treated with placebo and those treated with tiotropium amounts to $134 \mathrm{~mL}$ in morning trough FEV1 after 4 yrs of treatment or control. Taken together, the data strongly suggest that tiotropium, when used as a first-maintenance respiratory drug, has an effect beyond its acute bronchodilator effect and slows lung function deterioration in COPD.

Another interesting aspect of the current study is the effect on HRQoL. Few studies have looked at the effect of pharmacotherapy on long-term decline in HRQoL. Collectively, the present data show an acute effect on HRQoL. However, the most important effect was seen during follow-up. The effect of tiotropium treatment after 6 months was below the commonly accepted minimal clinically important difference (MCID) of 4 units (SGRQ score differed -2.29 units between groups). This difference is comparable to that reported in the whole UPLIFT ${ }_{B}$ cohort and is somewhat smaller than reported in other studies using tiotropium or other long acting bronchodilators [17, 18], which may reflect the increased use of concomitant respiratory medications in UPLIFT ${ }_{\circledast}$ relative to earlier trials. Interestingly, 

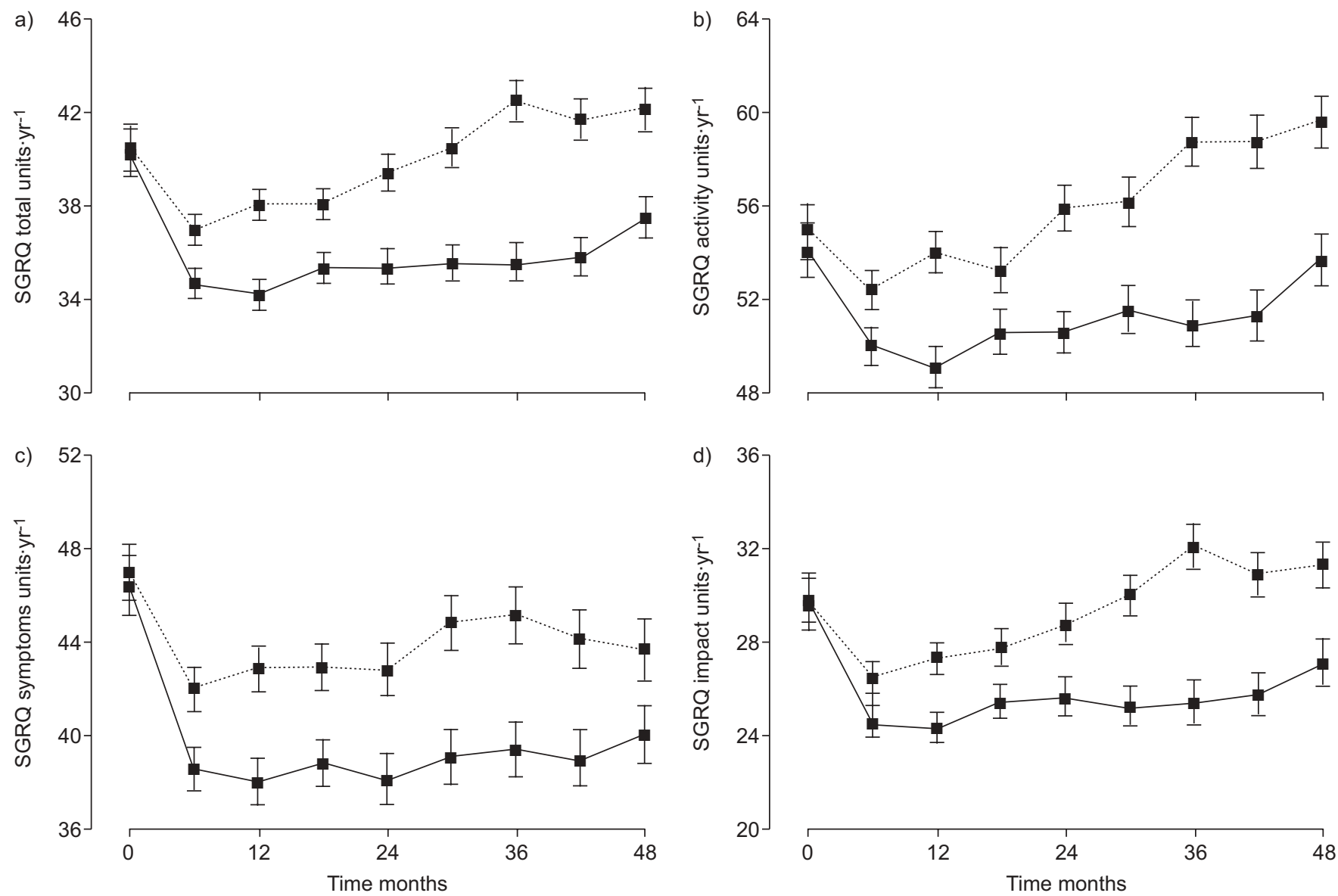

FIGURE 3. Mean St George's Respiratory Questionnaire (SGRQ) score in the tiotropium ( - ) and placebo (- - -) groups. a) Total score, b) activity domain, c) symptoms domain and d) impact domain.

the decline in HRQoL was slower in those patients who received tiotropium, and hence the difference between both groups became larger over time. The difference between groups exceeded the MCID (4 units) after 25.5 months and remained above the MCID thereafter. Clearly this illustrates the advantage of long-term studies, which permit a better insight into the long-term effects of respiratory drugs in patients with COPD. The difference in HRQoL deterioration between groups is comparable to that reported with fluticasone treatment in the Inhaled Steroids in Obstructive Lung Disease (ISOLDE) trial (1.17 units $\left.\cdot \mathrm{yr}^{-1}\right)$ [19]. In the ISOLDE trial, however, the overall decline in both groups was much faster (e.g. ISOLDE versus present study placebo groups 3.17 versus 1.71 units $\left.\cdot \mathrm{yr}^{-1}{ }^{-1}\right)$. This difference may at least be partially explained by the initial improvement seen after 2 weeks of prednisolone treatment at the beginning of the ISOLDE study [19], which subsequently lead to a more rapid deterioration. In the present study, the placebo group's annual decrease in HRQoL was comparable to that observed in the Bronchitis Randomized on NAC CostUtility Study (BRONCUS; 1.24 units $\cdot \mathrm{yr}^{-1}$ ) [20]. In BRONCUS, another trial in which concomitant medication was permitted, no effect on HRQoL decline was found with $600 \mathrm{mg} \cdot$ day $^{-1}$ of $N$-acetylcysteine administration. The annual reduction in the tiotropium group ( 0.66 units $\left.\cdot \mathrm{yr}^{-1}\right)$ is an important benefit when put in this context. It is difficult to compare the present data with the data obtained in TORCH because in that study, no data on decline in HRQoL are available. However, the treatment difference after 3 yrs of treatment in TORCH was -3.1 (95\% CI -4.1- -2.1) units in favour of the combination salmeterol plus fluticasone treatment compared to placebo, a group not permitted to use tiotropium, ICS or LABA [21]. In the present study, where other respiratory medications were permitted throughout the study, the difference at this time point (fig. 3) was significantly larger: -6.86 (95\% CI -9.2- -4.5) units.

The differences in the four domains of the SGRQ also merit attention. The symptom domain showed a rapid effect but the decline in this dimension was unaffected by tiotropium. The activity domain, however, was less improved after 6 months, but the decline in this domain was slowed down most by tiotropium treatment. This observation, which is consistent with the findings in ISOLDE [19], reinforces the hypothesis that changes in physical activity are an important consequence of COPD [22], and physical activity is likely to further reduce as the disease progresses [23]. Importantly, pharmacotherapy may impact on this patient-reported outcome but the impact is seen only after sufficient follow-up. PITTA et al. [24] have previously shown that enhancing physical activity may take time in COPD, even after an intervention as powerful as rehabilitation. The present data suggest that physical activity may be a particularly sensitive outcome to address disease progression and the impact of pharmacotherapy in COPD. 
The present study did not show significant effects of treatment with tiotropium on overall exacerbation rates. The number of patients experiencing exacerbations was low in comparison to the total UPLIFT ${ }_{\circledast}$ cohort, yielding a lower statistical power for this analysis. Although the reduction of the number of exacerbations per patient yr due to tiotropium was $16 \%$, which is comparable to the reduction seen in the full UPLIFT ${ }_{\circledast}$ cohort, this failed to reach statistical significance $(p=0.08)$. The number of patients experiencing an exacerbation was similar between groups, but there was a nonsignificant trend toward postponement of the first exacerbation (difference 6.3 months, HR 0.90 (95\% CI 0.75-1.08; $\mathrm{p}=0.24)$ ). The trends observed justify a larger study in similar patient cohorts as they may be of clinical relevance. Mortality was not statistically significantly different between groups, though the HR was consistent with that observed in the full cohort [5]. Unfortunately, the present analysis lacks the power to make final recommendations related to mortality.

The present data focus on an important clinical question regarding tiotropium as the initial maintenance treatment in COPD. However, the data reported in the present study are the result of secondary analyses of the UPLIFT ${ }_{\circledR}$ trial. Subgroup analyses may provide interesting information for clinicians but should always be interpreted with great caution. They should be used to guide further research rather than to draw final conclusions [25]. Nevertheless, subgroup analyses based on respiratory medication use were planned before unblinding in the statistical analysis plan (online supplementary material of TASHKIN et al. [4]). Due to the large sample size in UPLIFT ${ }^{\circledR}$, a sufficient number of patients are available from which to draw conclusions on the end-points of lung function and HRQoL. In order to draw valid conclusions regarding exacerbations and mortality, larger numbers of patients are needed. It is nevertheless interesting to note that the reductions in the risk of death were similar to the overall cohort and consistent with a beneficial effect. An important point of discussion is that patients could be prescribed other maintenance therapy during the study. Considering study completion without prescription of other maintenance therapy as successful treatment, $37 \%$ of patients in the tiotropium group and $28 \%$ of patients in the placebo group completed the protocol without starting additional maintenance therapy with either LABA and/or ICS. This further strengthens the present data as the initiation of other maintenance therapy in the placebo group may have biased against finding differences or reduced the magnitude of differences between groups, which may also have contributed to the lack of statistical significance on exacerbations.

In conclusion, the present study investigated the effect of tiotropium inhalation once daily in patients who did not receive other maintenance therapy at inclusion. Tiotropium treatment was associated with improvements in lung function and HRQoL. In addition, it was associated with slower disease progression. It also delayed the start of other maintenance medications and was associated with a non-statistically significant lower risk of mortality. The latter finding may be limited by the relatively small sample but is consistent with the overall study population. A trend was observed for a lower exacerbation rate and the first exacerbation was postponed, albeit nonsignificantly. The present analyses highlight the importance and need for prospective studies to specifically investigate the effects of pharmacotherapy in maintenance-naïve patients.

\section{SUPPORT STATEMENT}

The study was funded by Boehringer Ingelheim and Pfizer. The design of the trial, monitoring of the trial conduct, approval of the statistical analysis, review of the data, and writing of the manuscript involved a joint advisory committee including D.P. Tashkin, B. Celli, M. Decramer and S. Kesten. T. Troosters reviewed the data and participated in writing of the manuscript. S. Mehra reviewed the data and participated in writing of the manuscript. T. Lystig performed statistical analyses and participated in writing of the manuscript. Collection of the data and the statistical analyses were performed by employees of Boehringer Ingelheim. The decision to submit the manuscript involved all authors. All authors had full access to all of the data in the study and can take responsibility for the integrity of the data and the accuracy of the data analysis.

\section{CLINICAL TRIAL}

The present study is registered as a clinical trial at ClinicalTrials.gov (NCT00144339).

\section{STATEMENT OF INTEREST}

Statements of interest for all authors of this study, and for the study itself, can be found at www.erj.ersjournals.com/misc/statements.dtl

\section{ACKNOWLEDGEMENTS}

The investigators of the Understanding Potential Long-term Impacts on Function with Tiotropium (UPLIFT ${ }^{\circledR}$ ) trial are as follows (listed according to country). Argentina: E. Schiavi, J.C. Figueroa Casas, E. Rhodius, R. Gené, C.B. Sáenz, E. Giugno, C. Di Bartolo, M.C. De Salvo, E. Abbate, A.M. López. Australia: C. Steinfort, M. Peters, P. Carroll, G. Simpson, D. Freiberg, P. Fogarty, R. Watts, J. Wheatley. Austria: N. Vetter, O. Burghuber, C. Hesse, M. Flicker, C. Kähler. Belgium: G. Bral, K. Carron, D. Coolen, W. De Backer, T. De Beukelaar, M. Decramer, R. Deman, B. Dewispelaere, P. Driesen, W. Elinck, Y. Mentens, K. Vandeurzen, D. Van Renterghem, L. Van Zandweghe, W. Verhaeghe, W. Vincken, L. Delaunois, P. Duchatelet, A. Noseda, G. Nuttin, D. Rodenstein, A. Thibaut-Baudrez, G. Vandermoten, P. WackenierGenard, S. Baldassarre, M. Schlesser. Brazil: S.S. Menna Barreto, J.C. Corrêa, L.C. Corrêa da Silva, E. Fiss, A.M.S. Chibante, W.L.L. Dias de Mattos, C.C. Fritscher, J.A. de Oliveira, E. Pizzichini, M. Neves, A. Cruz, C.A. de Castro Pereira, A. Cukier, R. Stirbulov, J.R. Brito Jardim. Czech Republic: K. Kalandrova, M. Novakova, P. Hartman, V. Jensovsky, J. Vacek, V. Kasak, J. Erban, P. Kalina, J. Chlumsky, J. Musil, I. Hojka, A. Havlikova, J. Mares, K. Klenha, V. Vondra, M. Havlik, Z. Parakova, J. Vlcek, J. Dvorakova, H. Mazacova, D. Velart, L. Pospisil, O. Zajicova, P. Kolman, I. Binková, J. Fratrik. Denmark: P. Lange, V. Backer, R. Dahl; H. Harving, P. Tønnesen, E. Munch, O.B. Rasmussen, L. Tougaard, F. Egede, N.C. Hansen, A. Høegholm, F.V. Rasmussen, K.S. Jakobsen, J. Wessels, J.L. Frandsen, T. Evald, J. Hilskov, P. Garsdal, C. Nielsen, S. Haahr, J. Korsgaard, P.A. Revsbeck, J.G. Hansen, T. Soerensen, J.R. Arnved, A. Møller, H. Enevoldsen, M. Døssing, P. Christensen, K.D. Christensen, L. Frølund. Finland: K. Venho, M. Pietiläinen, P. Saarelainen, J. Kotaniemi, J. Männistö. France: M. Aubier, B. Pigearias, F. Malaquin, N. Grunchec, L. Bernabeu, B. Carme, A. Prud'homme, F. Bonte, D. Boz, R. Meunier; M-T. Rasolojaona, M. Apprill, R. Fargeon, P. Bernard, F. Tirouvanziam, M. Legendre, J-Y. Jasnot. Germany: M. Barczok, J.C. Becker, M. Pilz, V. Grimm-Sachs, M. Jahn, B. Kemmerich, W. Vorderstrasse, G. Klein, B. Kroemer, J. Lehnert, R. Redlich, S. Schmidtmann, T. Schultz, H-H. Weber. Greece: N. Siafakas, O. Anagnostopoulou, M. Toubis, K. Gourgoulianis, L. Sichletides, M. Kakoura, P. Christaki, I. Lychros, K. Spiropoulos, S. Bousmoukilia. Hong Kong: D.S.C. Hui, W.C. Yu, H.S. Chan, M.L. Wong. Hungary: Z. Baliko, M. Bisits, G. Böszörményi, M. Marton, K. Fonay, Z. Györi, L. Hajdu, J. Lukács, G. Kovacs, P. Magyar, G. Nagy, M. Namenyi, E. Meszaros, L. Petö, A. Somfay, Z. Kiraly, J. Strausz, Z. Szalai, M. Szilasi, B. Szima, Z. Sztancsik. Ireland: R. Costello, C. Burke. Italy: P.L. Paggiaro, P. Mazzocchi, C. Cattaneo, F. Peccini, M. Dottorini, M. Dottorini, R. Tazza, P. Pirina, F. Ginesu, R. Ortu, M. Sugamiele, M. Mastroberardino, G. Anzalone, G.W. Canonica, F. De Benedetto, 
F. Falcone, P. Greco, A. Papi, A. Ciaccia, R. Vincenti, G. Parentini, A. Tubaldi, V. De Rose, G. Ferretti, S. Gasparini, D. Legnani, G.P. Ligia, V. Padua, G. Santelli, F. Mazza, M.G. Boccieri, R. Cogo, A. Lopes Pegna, M. Pistolesi, V. Colorizio, P. Zanon. Japan: M. Nishimura, K. Yamauchi, H. Ogawa, T. Hattori, M. Ichinose, K. Kimura, N. Kaneko, K. Seyama, Y. Fukuchi, K. Kubo, H. Taniguchi, K. Hirata, Y. Tohda, H. Aizawa, S. Matsumoto. Lithuania: R. Sakalauskas, A. Bagdonas, R.V. Nargela. Malaysia: A.A. Mahayiddin, R. Harun, C.K. Liam. Mexico: J.R. Ortiz Peregrina, J.J. Díaz Castañón, R. Posadas Valay, R.H. Sansores Martínez, A.D. Peregrina. The Netherlands: J. van Noord, R. Aalbers, J.P.H.M Creemers, W.H. Dalinghaus, M.E. Eland, B.J.M. Pannekoek, H.R. Pasma, A. Rudolphus, H.E.J. Sinninghe Damsté, W.B.M. Evers, S.J.M. Gans, H. Timmer, J. Westbroek. New Zealand: P. Black, M. Epton. Norway: R, Dahle. A. Eivindson, J. Asmervik, P. Arve Lier. Philippines: L. Cañizares-Fernandez, A. Guzman-Banzon, T. Aquino, S. Sy-Naval, T. Trinidad. Poland: D. Gorecka, T. Piotr Plusa, E. Pisarczyk-Bogacka, P. Gorski, J. Kozielski, W. Pierzchala, A. Szczeklik, P. Kuna, J.M. Slominksi. Portugal: J. Almeida, R. Sá, C. Bárbara, R. Pato, J. Moita, J. Cardoso. Russia: A.G. Chuchalin, S. Ovtcharenko, V. Nonikov, M. Ilkovich, A. Tsoi. Singapore: Y.T. Wang, C. Lo, T.K. Lim. Slovakia: P. Kristufek, L. Chovan, E. Rozborilova, D. Salat, J. Plutinsky. Slovenia: S. Suskovic, M. Kosnik, M. Turel, L. Rezar, S. Ulcar-Kostic. South Africa: G.J. Ras, J.J. Du Toit, L. Herbst, M. van der Linden, A.M. Nel, J.J. Jansen, F.C.J. Bester, H.J.R. Colyn, I. Abdullah, I. Aboobaker Abdullah, E. Bateman. Spain: J.L.H. Budó, J.M. Pardo, M. Miravitlles; J.L. Izquierdo Alonso, P.V. Adán, J. Morera, J. Ferrer, J.L. Alvarez-Sala, J.F. Francés, F.F. Otero, M.J.F. Álvarez, H.V. Hernando, A.M. Pérez, S.H. Flix, A.S Bendito, R.B. Gimeno, T. Montemayor, C.V. Fernández-Montes, S.N Vazquez, V.S. Peña, M.R. Goday, A.B. Villar, R.B. Olivas, S.R. Candeira, A. Agustí, J. Ancochea, J.M.M. Trigo, J.M.R. González-Moro, B. Brotons, J. Merino, M.P. Tordera, F.O. Ruiz, Á.L. Encuentra, J.J. Batista, F.J.S Pinilla, R. Agüero. Switzerland: E. Russi, M. Solèr, M. Tamm, O. Bräendli, M. Pons, J-M. Tschopp, T. Hess. Taiwan: H-P. Kuo, G-M. Shiao. Thailand: C. Pothirat, S. Wongtim, S. Kiatboonsri, W. Dejsomritrutai, W. Boonsawat. Turkey: M. Erk, E. Tuncay, T. Celikel, B. Caglayan, L. Tabak, L. Çöplü, S. Ardiç, N. Ucar, A. Mirici, A. Kocabas, S. Erginel, A.H. Çimrin. UK: A. Mansur, C. Bucknall, P. Griffiths, D. Halpin, M. Morgan, A. Morice, P. Anderson, P. Plant, M. Britton, T. Harrison, S. Crooks, D. Shales, G. Douglas, J. Gravil. USA: M.D. Altose, T. Amgott, C.P. Andrews, C. Cote, F. Averill,W. Bailey, G. Bensch, E.R. Bleecker, D. Koh, M. Block, S. Braman, A.L. Brannen, S.A. Brazinsky, T. Bruya, D. Callahan, B. Celli, J.J. Condemi, B. Corser, J. Osmanski, T. Craig, A. Degraff, D.E. Doherty, M. Anderson, M. Doner, J. Donohue, M. Eichenhorn, N. Ettinger, J. Govert, R. Folz, J. Lasky, K. Kovitz, M. Friedman, G. Giessel, R. Pomerantz, G. Castillo, G.I. Greenwald, N. Hanania, R.D. Hautamaki, W. Henderson IV, A. Heyder, T. Hyers, J. Ilowite, M. Janes, R. Kahn, R. Harder, H. Kaiser, R.E. Kanner, M. Kaye, S. Kreitzer, D. Lawlor, I. Leech, B. Levine, M. Littner, N. Jarmukli, J. Liu, D.G. Lorch, D. Mahler, B. Make, M. Mandel, P. Mathur, D.H. Meyer, M.G. Milam, Z. Mohsenifar, T. Moriarty, J. Otoshi, R. Patel, A. Pratt, B. Prenner, J. Rehm, L. Repsher, A. Ries, K.B. Rock, A. Sharafkhaneh, G. San Pedro, P.D. Scanlon, P. Scheinberg, E.J. Schelbar, J. Schul, J. Fine, N. Segall, A. Seibert, G.L. Serfillipi, I. Spirn, R. Sussman, D. Tashkin, A. Wachtel, J. Westerman, R.A. Wise, R. Zielinski, R. ZuWallack, G. Ferguson, A. Gelb, W. Kuschner, K. Mahutte, F. Martinez, M. Plautz, C. Rochester, G. Schilero, G. Tino, G. Turino, J. Keppel.

\section{REFERENCES}

1 Pelkonen M, Notkola IL, Nissinen A, et al. Thirty-year cumulative incidence of chronic bronchitis and COPD in relation to 30-year pulmonary function and 40-year mortality: a follow-up in middleaged rural men. Chest 2006; 130: 1129-1137.

2 van Durme YM, Verhamme KM, Stijnen T, et al. Prevalence, incidence, and lifetime risk for the development of COPD in the elderly: the Rotterdam study. Chest 2009; 135: 368-377.
3 Rabe KF, Hurd S, Anzueto A, et al. Global strategy for the diagnosis, management, and prevention of chronic obstructive pulmonary disease: GOLD executive summary. Am J Respir Crit Care Med 2007; 176: 532-555.

4 Tashkin DP, Celli B, Senn S, et al. A 4-year trial of tiotropium in chronic obstructive pulmonary disease. N Engl J Med 2008; 359: 1543-1554.

5 Celli B, Decramer M, Kesten S, et al. Mortality in the 4-year trial of tiotropium (UPLIFT) in patients with chronic obstructive pulmonary disease. Am J Respir Crit Care Med 2009; 180: 948-955.

6 Decramer M, Celli BR, Tashkin DP, et al. Clinical trial design considerations in assessing long-term functional impacts of tiotropium in COPD: the "Uplift" trial. COPD 2004; 1: 151-160.

7 Jones PW, Quirk FH, Baveystock CM, et al. A self-complete measure of health status for chronic airflow limitation. The St. George's Respiratory Questionnaire. Am Rev Respir Dis 1992; 145: 1321-1327.

8 Quanjer PH, Tammeling GJ, Cotes JE, et al. Lung volumes and forced ventilatory flows. Report Working Party Standardization of Lung Function Tests, European Community for Steel and Coal. Official Statement of the European Respiratory Society. Eur Respir J 1993; 6: Suppl. 16, 5-40.

9 Standardization of Spirometry, 1994 Update. American Thoracic Society. Am J Respir Crit Care Med 1995; 152: 1107-1136.

10 Laird NM, Ware JH. Random-effects models for longitudinal data. Biometrics 1982; 38: 963-974.

11 Suissa S. Statistical treatment of exacerbations in therapeutic trials of chronic obstructive pulmonary disease. Am J Respir Crit Care Med 2006; 173: 842-846.

12 Celli BR, Thomas NE, Anderson JA, et al. Effect of pharmacotherapy on rate of decline of lung function in chronic obstructive pulmonary disease: results from the TORCH study. Am J Respir Crit Care Med 2008; 178: 332-338.

13 Tashkin DP, Celli B, Kesten S, et al. Long-term efficacy of tiotropium in relation to smoking status in the UPLIFT trial. Eur Respir J 2010; 35: 287-294.

14 Suissa S. Lung function decline in COPD trials: bias from regression to the mean. Eur Respir J 2008; 32: 829-831.

15 Decramer M, Celli B, Kesten S, et al. Effect of tiotropium on outcomes in patients with moderate chronic obstructive pulmonary disease (UPLIFT): a prespecified subgroup analysis of a randomised controlled trial. Lancet 2009; 374: 1171-1178.

16 Celli B, Kesten S, Lystig T, et al. COPD patients under 50 years of age: 4year follow-up in the UPLIFT trial. Eur Respir J 2009; 34: Suppl. 53, 674s.

17 Barr RG, Bourbeau J, Camargo CA, et al. Tiotropium for stable chronic obstructive pulmonary diesease, a meta-analysis. Thorax 2006; 61: 854-862.

18 Sin DD, McAlister FA, Man SF, et al. Contemporary management of chronic obstructive pulmonary disease: scientific review. JAMA 2003; 290: 2301-2312.

19 Spencer S, Calverley PM, Sherwood BP, et al. Health status deterioration in patients with chronic obstructive pulmonary disease. Am J Respir Crit Care Med 2001; 163: 122-128.

20 Decramer M, Rutten-van Molken M, Dekhuijzen PN, et al. The Bronchitis Randomized On NAC Cost-Utility Study (BRONCUS) Lancet 2005; 365: 1552-1560.

21 Calverley PM, Anderson JA, Celli B, et al. Salmeterol and fluticasone proprionate and survival in chronic obstructive pulmonary disease. $N$ Engl J Med 2007; 356: 775-789.

22 Pitta F, Troosters T, Spruit MA, et al. Characteristics of physical activities in daily life in chronic obstructive pulmonary disease. Am J Respir Crit Care Med 2005; 171: 972-977.

23 Watz HB, Waschki C, Boehme M, et al. Extrapulmonary effects of chronic obstructive pulmonary disease on physical activity. Am J Respir Crit Care Med. 2008; 177: 743-751.

24 Pitta F, Troosters T, Probst V, et al. Are patients with COPD more active after pulmonary rehabilitation? Chest 2008; 134: 273-280.

25 Rothwell PM. Treating individuals 2. Subgroup analysis in randomised controlled trials: importance, indications, and interpretation. Lancet 2005; 365: 176-186. 